\title{
The Acceptance and Use of Mobile Learning Applications in Higher Education
}

\author{
Mark Anthony Camilleri \\ University of Malta \\ Department of Corporate \\ Communication, Faculty of Media and \\ Knowledge Sciences \\ +3562340 3742 \\ mark.a.camilleri@um.edu.mt
}

\author{
Adriana Caterina Camilleri \\ Malta College of Arts, Sciences and \\ Technology \\ Institute of Community Services \\ +3562398 7100 \\ adriana.camilleri@mcast.edu.mt
}

How to Cite: Camilleri, M.A. \& Camilleri, A.C. (2019). The Acceptance and Use of Mobile Learning Applications in Higher Education. In Pfennig, A. \& Chen, K.C. (Eds.), $3^{\text {rd }}$ International Conference on Education and eLearning (ICEEL2019), Barcelona, Spain.

\section{This is a pre-publication version.}

\begin{abstract}
Many individuals are increasingly using ubiquitous technologies, including interactive applications (apps) that are widely available on our mobile devices, including the smart phones and tablets. Therefore, in the last few years, educators and policy makers have introduced mobile learning (m-learning) technologies in order to support their students during their learning journey. A thorough literature review suggests that there are several contributions in academia that have investigated the students' acceptance and use of technology, in different contexts. In this light, this research has integrated valid and reliable measures from the Technology Acceptance Model and the Theory of Planned Behavior to better understand the university students' readiness to engage with mobile technologies for educational purposes. Specifically, this study explores the perceived usefulness and ease of use of m-learning technologies. Moreover, it investigated whether the research participants were influenced by their friends, acquaintances and educators to engage with these technologies and / or by the facilitating conditions at their university. The findings revealed that students held positive attitudes toward the m-learning technologies as they perceived them as useful and easy to use. Moreover, the university's facilitating conditions had a significant effect on the students' usage of these technologies. This study also reported that the students' social influences did not have an effect on their intention to use these devices.
\end{abstract}

\section{Keywords}

Technology Acceptance Model, Theory of Planned Behavior, Unified Theory of Acceptance and Use of Technology, Mobile Learning, M-Learning, University, Higher Education.

\section{INTRODUCTION}

Portable communication devices, including; laptops, personal digital assistants (PDAs), and smart phones are connected to wireless networks. These mobile technologies allow individuals to access and review online content from virtually anywhere. Their applications (apps) can provide instant access to rich digital resources [1]. In higher education, these ubiquitous devices have become an integral aspect of the university student experience. M-learning apps are increasingly facilitating the interactions amongst peers through synchronous and asynchronous communications [2]. The students who use m-learning technologies interact with their instructors instead of hiding behind large monitors [3]. Arguably, it's much easier to use e-books that are accessible through mobile apps rather than having bags full of files, papers and textbooks, or even laptops. Notwithstanding, the mobile infrastructures, including hand-held technologies like tablets or smartphones are lighter and less bulky than desktop computers. Moreover, the students can use their mobile devices anywhere, anytime, including at home, and when they are out and about ([4], [5]). Hence, innovative m-learning technologies enable informal learning beyond the traditional classroom environment ([6], [7]). However, such pedagogies involving blended learning that incorporate educational technologies demand new approaches to delivering student-centered instruction ([8], [9]). Individuals are expected to possess digital skills to engage with the learning technologies. Therefore, non-technical individuals, including students as well as faculty employees ought to be facilitated through relevant instructional materials or collaborative learning when necessary. Alternatively, they may require training and professional development to remain up to date with the latest innovations.

Relevant academic literature suggests that mobile devices offer an equitable access to a wide plethora of digital learning resources ([10]). Today, many educators are shifting from being transmitters of knowledge to facilitators of learning as they use m-learning technologies in their classrooms. Course instructors can improve their students' motivation to learn if they utilize interactive media, as they can provide direct feedback or positive reinforcement in real time ([11]). Some apps can also engage students in immersive experiences through realistic simulations and serious (educational) games ([9], [12]). Previous research reported that many researchers have investigated the students' perceptions toward educational technologies ([11], [13]). Very often, they relied on the measures from the Technology Acceptance Model, the Theory of Planned Behavior or on the Unified Theory of Acceptance and Use of Technology, among others, to explore the students' behavioral intention to use educational technology ([14], [15], [16]. [17], [18]). 
However, there has been limited empirical research that identified the factors affecting the university students' adoption of m-learning technologies, albeit a few exceptions ([19], [20], [21], [22].

\subsection{The Research Question}

Many studies reported that that there are numerous benefits for students and instructors if they use m-learning technologies. Yet, there is no guarantee that they will be accepted and used in a higher educational context. There may be different factors that can have an effect on the students' readiness to adopt m-learning technologies. Hence, the rationale of this research is to better understand the students' disposition to utilize the m-learning technologies. Therefore, this study adds value to the extant literature in academia as it explores the students' attitudes toward m-learning. Specifically, it investigates the students' perceived usefulness and ease of use of m-learning. It also considers other factors, including the students' social influences as well as the facilitating conditions at their university as these issues may also have an effect on the students' intention to use m-learning. Perhaps, the students may lack the basic knowledge and skills to use m-learning technologies. Alternatively, they may not be encouraged by their course instructors to use mlearning applications to access their online resources.

It is hoped that the findings of this study will inform academic stakeholders, including researchers, instructors and policymakers about the current students' perceptions toward m-learning. Therefore, they will be in a position to plan, organize and implement educational programs that incorporate m-learning technologies to improve the students' outcomes.

\section{LITERATURE REVIEW}

\subsection{The Conceptual Development and the Formulation of Hypotheses}

M-learning can be implemented across different levels of education. However, it is highly relevant in the higher educational context, as the university students will already have their own mobile devices [22]. A thorough review of the literature suggests that there a few empirical studies that have explored the students' readiness to use the m-learning technologies; although there are a number of studies that have investigated the users' acceptance of other educational technologies, including; digital learning resources, WebCT or Moodle systems ([10], [19]). Very often these academic studies relied on valid and reliable measures that were drawn from the Theory of Reasoned Action, The Theory of Planned Behavior, the Technology Acceptance Model or the Unified Theory of Acceptance and Use of Technology, among others. Very often these theories suggested that the individuals' behavioral intention to use technological innovations is an important factor that determines whether they will actually utilize the mentioned technologies [18]

Many studies have explored the relationship between the behavioral intention and actual usage of technology in different contexts ([2], [4], [6], [21]). Their intention to use certain technologies could determine whether they will actually use (or reject) them [13]. There is a strong relationship between behavior intention (BIU) and actual usage (AU). This leads to the first hypothesis:

H1: The students' behavioral intention to use m-learning technologies is a significant antecedent for their actual usage.

The individuals' behavioral intention to use certain technologies could be determined by their attitude and is conditioned by the perceived usefulness and ease of use of information systems ([17]. [18]). Many academic studies have relied on the technology acceptance model (TAM)'s constructs to investigate the individuals' perceived usefulness and ease of use of technology ([19]). TAM has received empirical support in academia for being robust in predicting technology adoption in the realms of education ([5], [16], [20]). The perceived ease of use (PEoU) is the degree to which a person believes that using a particular system would be free of effort [15]. Therefore, the PEoU construct has a significant direct effect on the perceived usefulness (PU) of the technology [17]. In simple words, if the technology is easy to use the individuals can benefit from it. This leads to the second hypothesis:

H2: The students' perceived ease of use of the m-learning technologies has a positive and significant effect on perceived usefulness of the technology

PU has often been defined as the degree to which a person believes that using a particular system would enhance his or her job performance [10]. Hence, the PU construct is concerned with the expected overall impact of technology on the individual's job performance (in terms of process and outcome). PU has a direct effect on the individuals' intention to use. Other researchers contended that the individuals' behavioral intention is affected by attitude toward usage, as well as by the direct and indirect effects of PU and PEoU ([1], [5]. [18]). This argumentation leads to the following hypotheses:

H3: The students' perceived ease of use of the m-learning technologies has a positive and significant effect on their attitudes towards them.

H4: The students' perceived usefulness of m-learning technologies has a positive and significant effect on their attitudes toward them.

H5: The students' attitudes toward the m-learning technologies has a positive and significant effect on the behavioral intention to use them.

Other researchers recommended that TAM should be supplemented and extended by using the subjective norm ([15], [17]). Academic commentators argued that TAM should include variables that are related to both human and social change processes ([10], [14], [17]). Therefore, empirical studies have integrated elements from different theoretical models on technology acceptance and empirically validated them. Very often, they included external variables like subjective norms and facilitating conditions, among others, to examine the individuals' behavioral intentions to use educational technology ([13], [15]). The individuals' social influences (SI) was found to be a direct antecedent of behavioral intention to use the 
technology ([15], [17]) The individuals can be pressurized or influenced by their course instructors and / or by their peers.

Moreover, the universities' infrastructure and the provision of training, support, and access to technology can facilitate the individuals' readiness to use the technology ([15], [17]). The universities' facilitating conditions can be a direct antecedent for the individuals' intention to use the technology and / or for its usage. These arguments lead to the last hypotheses:

H6: The social influences will have a significant effect on the students' behavioral intention to use the m-learning technologies.

H7: The facilitating conditions have a significant effect on the students' behavioral intention to use m-learning technologies.

H8: The facilitating conditions have a significant effect on the students' usage of m-learning technologies.

\section{3: METHODOLOGY}

This study involved the administration of a survey questionnaire consisting of 26 multiple choice questions. The respondents could complete the questionnaire in less than ten minutes. They were expected to tick the most appropriate responses as they had to indicate their level of agreement to the survey's questions on a fivepoint Likert scale. Respondents were asked to indicate the strength of their agreement or disagreement with the statements. Responses were coded from 1 (strongly disagree) to 5 (strongly agree) with 3 signaling indecision.

The measuring items were adapted from previous studies that were tried and tested in academia ([5], [13], [14], [17], [18]. [20]). The survey questions of this research explored the participants' technology acceptance (10 items), social influences (3 items), facilitating conditions (4 items), behavioral intention (3 items) and usage of m-learning technologies ( 3 items). The participants revealed their level of agreement with the survey items in a five-point Likert scale. In the latter part of the questionnaire, the participants provided their demographic details, including gender, age and experience. The questionnaire was pilot tested to verify its appropriateness prior to the actual gathering of data from the targeted audience.

The research participants were all registered students who were following full-time or part-time courses at the University of Malta (UM). The university registrar forwarded an email cover letter that informed the students about the rationale of this study. It also provided some guidelines on how to complete the questionnaire. After two weeks, there were 138 valid responses.

\section{Results}

\subsection{The Research Participants}

The frequency table reported that there were seventy-five females and sixty-three males $(\mathrm{n}=138)$ who participated in this study. The respondents were classified into five age groups $(18-23 ; 24-29 ; 30-$ $35 ; 36-41$ and over 42 years of age). The majority of the research participants were aged between 18 and 23 years of age $(n=93)$, followed by those aged between 24 and 29 years $(n=27)$. The majority of respondents $(n=48)$ indicated that they had been using $m$ learning technologies between 2-3 years. Almost a quarter of the research participants $(n=33,24 \%)$ have used this technology for less than a year. Most of the respondents were following courses in Arts $(n=21)$, and this figure was closed followed by those who pursued courses in the realms of education $(n=19)$.

\subsection{The Descriptive Statistics}

The researcher assessed of the mean (M) scores, the standard deviations (SD) as well as the skewness and kurtoses of the responses. These values provided an indication on the students' perceptions towards the surveys' measuring items. The respondents indicated that they agreed with the questionnaire's statements, as there were high mean scores above the midpoint (3) that signaled a possible indecision. There was only one value (that represented a behavioral intention item) that was slightly below 3 (i.e. $\mathrm{M}=2.93$ ). Moreover, the SD indicated that there were small variances in the participants' responses. The values of the SD ranged from 0.743 to 1.31 , that indicated a narrow spread around the mean. The kurtosis index indicated that there was a normal distribution in the dataset except for PEoU1, PEoU2, PEoU3 and FC2. The distribution of values was not always symmetrical as the skewness value was more than twice its standard error for several items. Moreover, the distribution had a long-left tail for most items, as suggested by the negative skewness results.

\subsection{The Principal Component Analysis}

The Kaiser Meyer Olkin test that measures the sampling adequacy reported a KMO of 0.654 . This value was acceptable, as it was well above 0.5 (Field, 2005). Moreover, Bartlett's test of sphericity also revealed sufficient correlation in the dataset to run a principal component analysis (PCA) since $\mathrm{p}<0.001$. Therefore, the Principal Component Analysis (PCA) was used to assess the construct validity. PCA explored the degree to which a construct differs from other constructs (Ngai et al., 2007). At the same time, the data was compressed and reduced to obtain a factor solution of salient components that shared relevant similarities (and differences). The varimax rotation was used to reconstruct the seven composite factors. The factor loading referred to the correlation between each retained factor and each of the original variables (Kline, 2014). The factor loadings varied between -1 and +1 . Their values indicated the strength of relationship between a particular variable and the factor, in a way similar way to correlation. This study identified significant factor loadings of 0.5 or above as per Hair et al.'s s (1999) recommendations for small samples (where $n=120$ ). In this case, there were 138 respondents $(\mathrm{n}=138)$.

Typically, the variables with the highest correlation scores had mostly contributed towards the make-up of each component. The factors components accounted for $76 \%$ of the variance. The Cronbach's alpha assessed the reliability of the multi-item scales used in this study. The findings reported alpha values that were higher than 0.7 (i.e. the recommended threshold) for all constructs. The alpha coefficient ranged from 0.76 to 0.92 . These results suggest that the measures were reliable and internally consistent. Table 1 presents the results of the principal component analysis. It features the seven extracted factor components, together with their respective eigenvalues, cumulative variance explained (\%) as well as Cronbach's alpha. 
Table 1. Results from the Principal Component Analysis

\begin{tabular}{|c|c|c|c|c|c|c|c|}
\hline \multirow[t]{2}{*}{ Component } & \multicolumn{3}{|c|}{ Initial Eigenvalues } & \multicolumn{3}{|c|}{$\begin{array}{l}\text { Rotation Sum of } \\
\text { Square Loadings }\end{array}$} & \multirow[t]{2}{*}{ Alph } \\
\hline & Eig. & $\begin{array}{l}\% \text { of } \\
\text { Var. }\end{array}$ & Cum. $\%$ & Eig. & $\begin{array}{l}\% \text { of } \\
\text { Var. }\end{array}$ & Cum. $\%$ & \\
\hline $\begin{array}{l}1 \text { Perceived } \\
\text { Ease of Use } \\
\text { (PEoU) } \\
\end{array}$ & 4.800 & 25.468 & 25.468 & 3.226 & 17.117 & 17.117 & 0.92 \\
\hline $\begin{array}{l}2 \text { Behavioral } \\
\text { Intentions (BI) }\end{array}$ & 2.526 & 13.399 & 38.868 & 2.190 & 11.620 & 28.737 & 0.89 \\
\hline $\begin{array}{l}3 \text { Social } \\
\text { Influences (SI) }\end{array}$ & 2.202 & 11.681 & 50.549 & 1.852 & 9.823 & 38.560 & 0.86 \\
\hline $\begin{array}{l}4 \text { Perceived } \\
\text { Usefulness } \\
(\mathrm{PU}) \\
\end{array}$ & 1.597 & 8.471 & 59.020 & 2.000 & 10.611 & 49.171 & 0.85 \\
\hline $\begin{array}{l}5 \text { Facilitating } \\
\text { Conditions } \\
(\mathrm{FC}) \\
\end{array}$ & 1.305 & 6.921 & 65.941 & 2.386 & 12.658 & 61.828 & 0.82 \\
\hline 6 Attitude (A) & .994 & 5.276 & 71.216 & 1.639 & 8.697 & 70.526 & 0.79 \\
\hline $\begin{array}{l}7 \text { Use } \\
\text { (U) }\end{array}$ & .922 & 4.892 & 76.109 & 1.052 & 5.583 & 76.109 & 0.76 \\
\hline
\end{tabular}

\subsection{Multivariate Regression Analysis}

The researchers relied on a regression analysis to investigate the hypothesized relationships of this study. We chose the stepwise procedure to identify the significant constructs, where the p-value was less than the 0.05 benchmark Therefore, the insignificant variables were excluded without appreciably increasing the residual sum of squares. The first five hypotheses tested the hypothesized relationships appertaining to the Technology Acceptance Model, whilst the latter three hypotheses integrated other constructs, namely; social influences and facilitating conditions.

H1: The results from the regression analysis suggested that behavioral intention anticipated the usage of technology, where the adj. $\mathrm{r} 2=0.418$ and the $\mathrm{t}$ value $=2.235$ ). This relationship was significant as $\mathrm{p}=0.026$. H2: There was also a positive and significant relationship between the students' perceived ease of use of the mlearning technologies and their perceived usefulness of the technology where the adj. $\mathrm{r} 2=0.303$ and the $\mathrm{t}$ value $=1.904$. This relationship was significant as $p=0.043$. H3: The students' perceived ease of use of the m-learning technologies had a positive and very significant effect $(\mathrm{p}<0.001)$ on their attitudes towards them. The adj. $\mathrm{r} 2=0.157$ and the $\mathrm{t}$ value $=4.877$. H4: Similarly, the students' perceived usefulness of m-learning technologies had a positive and highly significant effect $(\mathrm{p}<0.001)$ on their attitudes toward them. The adj. $\mathrm{r} 2=0.163$ and $\mathrm{t}=3.984$. H5: Moreover, there was also a positive and significant relationship between the students' attitudes toward the m-learning technologies and their behavioral intention to use them as adj. $\mathrm{r} 2=0.111$ and $\mathrm{t}$ value $=5.136$. The measurement of significance indicated a confidence level of $97 \%$ (where $p=0.03$ ).

H6: The individuals' social influences did not have a significant effect on the students' behavioral intention to use the m-learning technologies. In this case the results were inconclusive as p H7: There were no significant relationships between facilitating conditions and behavioral intention to use m-learning technologies. Again, the findings were inconclusive as $p>0.05$. H8: Nevertheless, there facilitating conditions had a significant effect $(\mathrm{p}=0.02)$ on the students' usage of m-learning technologies, where adj. $r 2=0.435$ and $\mathrm{t}$ value $=13.608$

\section{Conclusions and Implications}

This study has validated previous empirical work in academia as it explored the research participants' technology acceptance to use the $\mathrm{m}$-learning technologies. The findings revealed the factors that were having the most significant effect on the students' engagement with the mentioned technologies in a higher educational institution from southern Europe. The results were congruent with other recent studies that have explored the use of technologies in higher education. The descriptive statistics indicated that the participants perceived the m-learning technologies as easy to use (PEoU). Moreover, there were high mean scores that were reported for the facilitating conditions (FC) and when the students' indicated their level of agreement with the survey items appertaining to the usage of technology (U). The results from the principal component analysis also revealed that the most determining factors behind the students' engagement with this learning technology was its simplicity and ease of use (PEoU). This issue probably had an effect on the individuals' intention (BI) to use the technology in the future. This was clearly evidenced in the factor analysis.

The regression analysis clearly evidenced the positive and significant relationships of tested hypotheses. The perceived usefulness (PU) was significantly corelated with perceived ease of use (PEoU) and both constructs were the antecedents of attitude toward use. Moreover, the latter construct together preceded intention (BI). Notwithstanding, this study found a highly significant relationship between the university's facilitating conditions (FC) and the students' utilization of the mentioned learning technology (U). On the other hand, this study reported that there was no significant relationship between facilitating condition (FC) and behavioral intention (BI). This study also indicated that there was no positive and significant relationship between the students' social influences (SI) and their intention (BI) to use the technologies. Similar findings reported that the subjective norm (this is related to social influences) had a negative impact on intention [15]. However, other researchers found that the students are influenced by their course instructors to use the university's technologies at their disposal ([7], [19], [21]). mobile technologies for utilitarian motives.

In conclusion, this research has shown that the m-learning technologies are increasingly being utilized by many students hailing from different faculties. The students themselves indicated that they considered these resources as necessary to improve their learning journey. Hence, there is scope for the university educators and policy 
makers to create and adopt m-learning technologies in addition to traditional teaching methodologies, to deliver quality education.

The researcher relied on a linear regression analysis to explore the students' acceptance and usage of m-learning in higher education. The number of respondents was more than sufficient to draw significant inferences from the results. However, further research is necessary to identify the factors that facilitate or hinder the students' engagement with these education technologies. A qualitative study could reveal the students' in-depth opinions and personal experiences on m-learning. Future studies can investigate the strengths and weaknesses of using these innovative resources for specific subjects. Other research can shed more light on the design, structure and content of m-learning resources that are intended to facilitate the students' learning experience via their mobile apps. Moreover, longitudinal studies could possibly provide a better understanding of the students' engagement with these learning technologies. The students' attitudes and perceptions towards m-learning can change over time, particularly as they become experienced users.

\section{ACKNOWLEDGMENTS}

Our thanks to the ICEEL Conference Chairs and to their reviewers.

\section{REFERENCES}

[1] Cheon, J., Lee, S., Crooks, S. M., \& Song, J. (2012). An investigation of mobile learning readiness in higher education based on the theory of planned behavior. Computers \& Education, 59(3), 1054-1064.

[2] So, S. (2016). Mobile instant messaging support for teaching and learning in higher education. The Internet and Higher Education, 31, 32-42.

[3] Nassuora, A. B. (2012). Students acceptance of mobile learning for higher education in Saudi Arabia. American Academic \& Scholarly Research Journal, 4(2), 24-30.

[4] Camilleri, A.C. \& Camilleri, M.A. (2019a). Mobile Learning via Educational Apps: An Interpretative Study. In Shun-Wing N.G., Fun, T.S. \& Shi, Y. (Eds.) 5th International Conference on Education and Training Technologies (ICETT 2019). Seoul, South Korea (May, 2019). International Economics Development and Research Center (IEDRC).

[5] Camilleri, M.A. \& Camilleri, A. (2017a). Measuring The Educators' Behavioural Intention, Perceived Use And Ease Of Use Of Mobile Technologies. In Wood, G. (Ed) Re-connecting management research with the disciplines: Shaping the research agenda for the social sciences (University of Warwick, September). Proceedings, pp., British Academy of Management, UK.

[6] Henderson, M., Selwyn, N., \& Aston, R. (2017). What works and why? Student perceptions of 'useful'digital technology in university teaching and learning. Studies in Higher Education, 42(8), 1567-1579.

[7] Camilleri, M.A. \& Camilleri, A. (2017b). The Technology Acceptance of Mobile Applications in Education. In Sánchez, I.A. \& Isaias, P. (Eds) 13th International Conference on Mobile Learning (Budapest, 11th April). Proceedings, pp4148. International Association for Development of the Information Society.

[8] Corbeil, J. R., \& Valdes-Corbeil, M. E. (2007). Are you ready for mobile learning? Educause Quarterly, 30(2), 51-59.
[9] Camilleri, M.A. \& Camilleri, A.C. (2019d). Student-Centred Learning through Serious Games. 13th Annual International Technology, Education and Development Conference. Valencia, Spain (March, 2019). International Academy of Technology, Education and Development (IATED).

[10] Camilleri, M. A., \& Camilleri, A. C. (2017). Digital learning resources and ubiquitous technologies in education. Technology, Knowledge and Learning, 22(1), 65-82.

[11] Jeong, H. I., \& Kim, Y. (2017). The acceptance of computer technology by teachers in early childhood education. Interactive Learning Environments, 25(4), 496-512.

[12] Camilleri, M.A. \& Camilleri, A. (2017c). The Students' Perceptions of Digital Game-Based Learning. In Pivec, M. \& Grundler, J. (Ed.) 11th European Conference on Games Based Learning (October). Proceedings, pp. 52-62, H JOANNEUM University of Applied Science, Graz, Austria, pp 56-62.

[13] Teo, T., \& Zhou, M. (2014). Explaining the intention to use technology among university students: a structural equation modeling approach. Journal of Computing in Higher education, 26(2), 124-142.

[14] Teo, T. (2009). Modelling technology acceptance in education: A study of pre-service teachers. Computers \& Education, 52(2), 302-312.

[15] Teo, T., \& Beng Lee, C. (2010). Explaining the intention to use technology among student teachers: An application of the Theory of Planned Behavior (TPB). Campus-Wide Information Systems, 27(2), 60-67.

[16] Camilleri, A.C. \& Camilleri, M.A. (2019b). The Students Intrinsic and Extrinsic Motivations to Engage with Digital Learning Games. In Shun-Wing N.G., Fun, T.S. \& Shi, Y. (Eds.) 5th International Conference on Education and Training Technologies (ICETT 2019). Seoul, South Korea (May, 2019). International Economics Development and Research Center (IEDRC).

[17] Venkatesh, V., Morris, M. G., Davis, G. B., \& Davis, F. D. (2003). User acceptance of information technology: Toward a unified view. MIS quarterly, 27(3), 425-478.

[18] Davis, F. D. (1989). Perceived usefulness, perceived ease of use, and user acceptance of information technology. MIS quarterly, 13,(3), 319-340.

[19] Cheung, R., \& Vogel, D. (2013). Predicting user acceptance of collaborative technologies: An extension of the technology acceptance model for e-learning. Computers \& Education, 63, 160-175.

[20] Camilleri, A.C. \& Camilleri, M.A. (2019c). The Students' Perceived Use, Ease of Use and Enjoyment of Educational Games at Home and at School. 13th Annual International Technology, Education and Development Conference. Valencia, Spain (March, 2019). International Academy of Technology, Education and Development (IATED).

[21] Briz-Ponce, L., Pereira, A., Carvalho, L., Juanes-Méndez, J. A., \& García-Peñalvo, F. J. (2017). Learning with mobile technologies-Students' behavior. Computers in Human Behavior, 72, 612-620.

[22] Jeno, L. M., Adachi, P. J., Grytnes, J. A., Vandvik, V., \& Deci, E. L. (2019). The effects of m-learning on motivation, achievement and well-being: A Self-Determination Theory approach. British Journal of Educational Technology, 50(2), 669-683. 


\section{Authors' background}

\begin{tabular}{|l|l|l|l|}
\hline Your Name & Title $^{*}$ & Research Field & Personal website \\
\hline Mark Anthony Camilleri & Associate Professor & $\begin{array}{l}\text { Digital Media } \\
\text { Technology Acceptance }\end{array}$ & https://www.um.edu.mt/profile/markacamilleri \\
\hline $\begin{array}{l}\text { Adriana Caterina } \\
\text { Camilleri }\end{array}$ & Senior Lecturer & $\begin{array}{l}\text { Education Technology } \\
\text { Psychology }\end{array}$ & $\underline{\text { https://mt.linkedin.com/in/adriana-camilleri- }}$ \\
\hline
\end{tabular}

